\title{
Use of Retroactive Pessimism as a Method of Coping with Identity Threat: The Impact of Group Identification
}

\author{
Daniel L. Wann \\ Murray State University \\ Frederick G. Grieve \\ Western Kentucky University
}

\section{Paula J. Waddill and Jennifer Martin}

Murray State University

\begin{abstract}
Retroactive pessimism involves retrospectively lowering one's evaluations of a group's chances for success after a failed competition. Although past research has substantiated the existence of this strategy, investigators have yet to examine how level of group identification might impact the use of retroactive pessimism. Given that coping with group threat is most prominent among persons with high levels of group identification, we hypothesized that displays of retroactive pessimism would be magnified in persons with strong allegiances to a group. This hypothesis was tested by having supporters of two college basketball teams evaluate the chances for victory for each team both prior to the game between the teams and subsequent to the contest. Regression analyses confirmed expectations (the greatest magnitude of retroactive pessimism was reported by highly identified supporters of the losing team in their evaluations of the winning team). Subsequent analyses revealed that this effect was not mediated by level of disappointment in the outcome.
\end{abstract}

KEYWORDS coping with group threat, group identification, retroactive pessimism

Psychological research on the hindsight bias (Hawkins \& Hastie, 1990; Slovic \& Fischhoff, 1977) indicates that once the outcome of an event becomes a reality, individuals often reconstruct their explanations for the outcome. According to work by Blank and his colleagues (Blank, Fischer, \& Erdfelder, 2003; Blank \& Nestler, 2006), there appear to be three relatively distinct components to the hindsight bias: foreseeability, perceptions of necessity, and memory distortions. Foreseeability concerns our tendency to overestimate the predictability

\section{$\overline{\text { Author's note }}$}

Address correspondence to Daniel L. Wann, PhD, Department of Psychology, Murray State University, Murray, KY 42071, USA [email: dan.wann@murraystate.edu] 
of an outcome. Necessity involves our tendency to perceive a passed outcome as inevitable. Memory distortions involve our 'tendency to misremember', for example, our tendency to recall predictions as more accurate than they actually were.

Recently, Tykocinski and her colleagues provided evidence for a specific hindsight bias they refer to as retroactive pessimism (Tykocinski, 2001; Tykocinski, Pick, \& Kedmi, 2002). Retroactive pessimism occurs when, subsequent to a disappointing outcome, individuals re-evaluate their group's chances for success, concluding that, 'We never really had a chance, anyway.' By adopting such a deterministic belief, persons are better able to cope with threats to their social identity. ${ }^{1}$ Because such cognitions involve concluding that an outcome was inevitable, retroactive pessimism is an example of the necessity component of hindsight bias and research indicates that strategic perceptions of necessity can be effective as a coping strategy (Blank \& Nestler, 2006).

Several studies have documented the existence of retroactive pessimism. For example, Tykocinski et al. (2002) asked fans of two soccer teams to rate their team's chances of victory in an upcoming match both prior and subsequent to the contest. Results indicated that supporters of the winning team reported little change in their pre- to post-match ratings of the teams' chances. Such a finding was expected as these persons had little reason to exhibit retroactive pessimism. Conversely, fans of the losing team significantly altered their pre- to post-game perceptions of the teams' chances, reporting that the winning team was more likely to win and the losing team more likely to lose after the competition had taken place. Thus, by adopting a retroactively pessimistic belief that a negative outcome was most likely inevitable, individuals may better cope with a threat to their social identity.

However, one would not expect all group members to act in such a manner. Research on social identity theory (Hogg \& Abrams, 1988; Tajfel \& Turner, 1986) indicates that attempts to cope with threat are most prominent among persons with a high degree of group identification
(Branscombe, Ellemers, Spears, \& Doosje, 1999; Doosje, Branscombe, Spears, \& Manstead, 1998; Wann \& Schrader, 2000). For these persons, the group or team's performance has relevance to a central component of a valued social identity. For persons with low levels of identification, the role of group member or team follower is only a peripheral component of their identity, at best (Branscombe, Wann, Noel, \& Coleman, 1993; Crocker \& Major, 1989). Consequently, these individuals do not feel threatened by poor group performance and have little need to employ coping strategies. Rather, it is 'the combination of an identity threat and strong ingroup identification that elicits group-oriented coping responses' (Ouwerkerk, Ellemers, \& de Gilder, 1999, p. 185; see also Doosje, Ellemers, \& Spears, 1999; Spears, Doosje, \& Ellemers, 1997).

The current investigation was designed to expand on Tykocinski's research (Tykocinski, 2001; Tykocinski et al., 2002) by examining the impact of identification on expressions of retroactive pessimism among fans of two college basketball teams. Consistent with Tykocinski, participants rated each team's chances of success both prior to a game involving the target teams and subsequent to the contest. With respect to replication of Tykocinski et al. (2002), we expected our respondents to report a similar pattern of retroactive pessimism in which supporters of the eventual losing team would, in retrospect, report lower chances of victory for their team and higher chances of victory for their opponent. Also consistent with the previous work, supporters of the successful team were not expected to exhibit retroactive pessimism because their identity had not been threatened. Thus, we hypothesized that there would be a significant three-way interaction involving the team supported (winner or loser), the team evaluated (winner and loser), and testing session (before the contest and after the contest). Tykocinski and her associates also examined the relationships between the degree of post-game evaluation shifts and emotional reactions to the contest (i.e. happy/ disappointed) for supporters of the losing team. These authors noted that if use of the hindsight bias is a function of distress from an event, one 
should find a relationship between magnitude of the bias and distress level. Consequently, we hypothesized a pattern in which larger pre- to post-game shifts would be associated with greater levels of disappointment. However, in an attempt to expand on Tykocinski et al.'s (2002) findings, participants reported their identification with their team during the Time 1 session. Consistent with the aforementioned work in social identity theory (Branscombe et al., 1999; Ouwerkerk et al., 1999), we expected to find that the use of retroactive pessimism was most prominent among highly identified persons.

With respect to relationships among degree of post-game evaluation shifts, emotional reactions to the contest, and level of identification, research indicates that identification is critical in predicting the intensity of emotional reactions subsequent to watching one's group perform (Hirt, Zillmann, Erickson, \& Kennedy, 1992; Wann, Dolan, McGeorge, \& Allison, 1994). Consequently, we expected highly identified persons to report more intense postgame emotional responses than those low in identification. Specifically, highly identified supporters of the winning team should report particularly high levels of happiness, whereas highly allegiant followers of the losing team should report more intense levels of disappointment. We further investigated the relationships among these variables through the use of mediated moderated regression to determine if differences in post-game shifts as a function of identification and team supported were mediated by emotional reactions to the outcome.

\section{Method}

\section{Participants}

The original sample of participants comprised 173 students at one of two mid-southern universities (Murray State University, MSU, and Western Kentucky University, WKU). Participants earned extra course credit in their psychology course in exchange for participation. Thirteen persons failed to complete all forms and 24 additional participants were not aware of the outcome of the target basketball contest. Thus, these 37 individuals were dropped from the data set resulting in a final sample of 136 participants (54 male, 82 female; MSU $n=84$, WKU $n=52)$. They had a mean age of 21.13 years $(S D=2.64$, range $=18-34)$.

\section{Materials and procedure}

Pre-test session The pre-testing sessions occurred at both universities between one and five days prior to the target basketball contest involving the schools. Upon entering the testing room and providing their consent, participants (tested in groups) completed a questionnaire packet containing three sections. The first section contained demographic items assessing age and gender, and requested the last four digits of the participant's social security number (for pre- and post-test matching purposes). The second section contained the Sport Spectator Identification Scale (SSIS; Wann \& Branscombe, 1993). The SSIS contains seven Likert-type items with response options ranging from 1 (low identification) to 8 (high identification). Participants targeted their university's (i.e. MSU or WKU) men's basketball team when completing the SSIS. The items comprising the SSIS were (response options are in italics):

1. How important to you is it that (target team) wins? (not important/very important).

2. How strongly do YOU see YOURSELF as a fan of (target team)? (not a fan/very much a fan).

3. How strongly do your FRIENDS see YOU as a fan of (target team)? (not a fan/very much a fan).

4. During the season, how closely do you follow (target team) via ANY of the following: (i) in person or on television; (ii) on the radio, (iii) television news or a newspaper; or (iv) the Internet? (never/almost everyday).

5. How important is being a fan of (target team) to YOU? (not important/very important).

6. How much do you dislike the greatest rivals of (target team)? (do not dislike/dislike very much).

7. How often do YOU display (target team's) name or insignia at your place of work, where you live, or on your clothing? (never/ always). 
The seven items comprising the SSIS were combined to form a single index of team identification (Cronbach's alpha $=.94$ ).

The final section of the pre-test packet contained two items assessing perceptions of the teams' chances of victory. For replication purposes, the phrasing of the items was identical to that used by Tykocinski et al. (2002) in their work with soccer teams, with the exception of the teams' names. Participants were asked to 'rate the chances of Murray State University winning the game' and to 'rate the chances of Western Kentucky University winning the game.' Response options ranged from 1 (almost zero chance) to 9 (very high chance). Upon completion of the packet, participants were given information on the time and place for the post-test sessions. They were then excused from the session.

Post-test session During the post-test session, which occurred between two and five days following the game, participants (tested in groups) completed a questionnaire containing five items. The first item requested the participant's social security number (last four digits) for matching purposes. The second item asked participants to indicate who had won the game. Participants were to circle either Murray State University or Western Kentucky University. The third and fourth items were similar to the perception of victory items contained in the pre-test, with the difference being a focus on retrospection rather than prediction. Specifically, these items read, 'Now that the game has been played, in retrospect, what in fact were the chances of Murray State University winning the game?' and 'Now that the game has been played, in retrospect, what in fact were the chances of Western Kentucky University winning the game?' Once again, this wording was based on that used by Tykocinski et al. (2002) and response options ranged from 1 (almost zero chance) to 9 (very high chance). The fifth and final item assessed emotional reactions to the game. Respondents indicated 'how you felt about the outcome of the game' using a scale of 1 (very disappointed) to 9 (very happy) (the wording and anchors were identical to those of Tykocinski et al.). Upon completion of the post-test packet, participants were handed a debriefing statement explaining the hypotheses of the study and containing information on gaining access to a copy of the results.

\section{Target game}

The game was an early season, non-conference contest between two NCAA Division I men's basketball teams who are traditional rivals (the schools are located only 120 miles apart). The home team had a record of two wins and one loss entering the contest, while the visiting team had a mark of two wins and two losses. The game was relatively close throughout, with the home team (MSU) holding a 44-34 advantage at half time. MSU eventually won the contest by a score of MSU 83 and WKU 72. An analysis of variance (ANOVA) revealed that visiting fans $(M=26.13, S D=11.28)$ and home fans $(M=26.56, S D=13.90)$ did not differ in their average level of identification, $F(1,134)=0.04$, $p=.85$.

\section{Results}

\section{Replication of Tykocinski et al. (2002)}

The first series of analyses involved attempts to replicate those of Tykocinski et al. (2002). Hence, these analyses were conducted across identification groups. The first analysis examined emotional reactions to the game. This ANOVA revealed that, as expected, fans of the losing team were less pleased (i.e. more disappointed) with the outcome $(M=3.63, S D=1.70)$ than fans of the winning team $(M=7.35, S D=1.65)$ $(F(1,134)=158.85, p<.001)$. The next set of analyses examined participants' ratings of the teams' chances for victory before and after the game. The initial analysis involved a 2 (Team Supported: winner or loser) $\times 2$ (Team Evaluated: winner and loser) $\times 2$ (Time: before the contest and after the contest) mixed ANOVA. The first variable was between-subjects while the last two were repeated measures within-subjects. As predicted, this analysis revealed a significant Team Supported by Team Evaluated by Time three-way interaction, $F(1,134)=7.39, p<.01$. Shown in Table 1 , this 
Table 1. Means and standard deviations by team supported (winner or loser), team evaluated (winner and loser), and time (before the contest and after the contest)

\begin{tabular}{lccccc}
\hline & \multicolumn{2}{c}{ Evaluation of winner } & & \multicolumn{2}{c}{ Evaluation of loser } \\
\cline { 2 - 3 } & Time 1 & Time 2 & & Time 1 & Time 2 \\
\hline Supporter of winner & 5.57 & 5.96 & 5.17 & 4.57 \\
Supporter of loser & $(1.56)$ & $(1.77)$ & 5.63 & $(1.89)$ & $(1.98)$ \\
& 4.31 & $(1.83)$ & $(1.42)$ & 5.02 & $(1.80)$ \\
\hline
\end{tabular}

Note: Standard deviations appear in parentheses below each mean.

interaction replicates the findings reported by Tykocinski et al. (2002). Specifically, although fans of both teams retrospectively decreased their evaluations of the chances for the losing team and increased their ratings of the chances for the winning team, this pattern of effects was much more pronounced among persons supporting the losing team (results of tests of specific comparisons and information on main effects and two-way interactions are available upon request).

The final set of replication analyses involved examining correlations between the degree of post-game shift and emotional reactions to the contest. It was hypothesized that there would be a significant correlation between magnitude of the pre- to post-game bias and distress level. To test this possibility, pre- to post-game shifts were calculated (i.e. difference scores) and separate correlations were calculated with the item assessing emotional reactions to the game for fans of the winning and the losing team. Consistent with the findings reported by Tykocinski et al. (2002), a significant negative correlation was found among fans of the losing team, $(r=-.37$, $p<.01$ ), but no relationship was found for supporters of the winning team, $r=-.05, p<.60$. Thus, high pre-game to post-game shifts were associated with greater levels of disappointment only for fans of the losing team. ${ }^{2}$

\section{Examination of the impact of team identification}

Although the earlier analyses provided strong replication of Tykocinski et al.'s (2002) research, the primary purpose of the current investigation was to extend the earlier work by testing the hypothesis that the pattern of effects detailed earlier would be most prominent among persons with a high degree of team identification for one of the competitors. The initial test of this hypothesis involved a moderated regression analysis on the dependent variable of post-game shift (calculated as the difference between the post-game evaluation of a team's chances of winning and the pre-game evaluation of that team's chances). Means, standard deviations, and intercorrelations among the variables are presented in Table 2. Separate hierarchical regression analyses were conducted for postgame evaluation shifts for the winning team and the losing team. Following the recommendations of Aiken and West (1991), the team identification variable was centered prior to entering it into the analysis and the interaction term was based on that centered score. In both analyses, shift score was first regressed on team supported and team identification. In the second step, the interaction variable was introduced. The results of these analyses are presented in Table 3. Regressing the dependent variables on team support and team identification resulted in an $R^{2}$ of .079 for winning team post-game shift $(p<.01)$, and an $R^{2}$ of .037 for losing team post-game shift $(p=.083)$. The introduction of the interaction term accounted for a significant additional proportion of variance in winning team shift $\left(\Delta R^{2}=.037, p<.05\right)$ but not in losing team shift $\left(\Delta R^{2}=0.0, p=.970\right)$. The final equation for winning team shift revealed two significant predictors: team supported $(\beta=.229, p<.01)$ and the interaction between team supported and 
Table 2. Means, standard deviations, and correlations among shifts in teams' chances, team identification, emotional response, and team supported

\begin{tabular}{lccccc}
\hline Variable & 1 & 2 & 3 & 4 & 5 \\
\hline Shift in winner's chances (1) & - & & & & \\
Shift in loser's chances (2) & $-.361^{* *}$ & - & & \\
Team identification (3) $_{\text {Emotional response }^{\mathrm{a}}(4)}$ & .162 & -.127 & - & \\
Team supported $^{\mathrm{b}}(5)$ & $-.171^{*}$ & .101 & .018 & - & \\
$M$ & $.232^{* *}$ & -.146 & .017 & $-.736^{* *}$ & - \\
$S D$ & .75 & -.82 & 26.29 & 5.93 & - \\
\hline
\end{tabular}

Note: $N=136$.

${ }^{\mathrm{a}}$ Rated on a scale from 1 (very disappointed) to 9 (very happy). ${ }^{\mathrm{b}}$ Coded as: winning team $=0$, losing team $=1$. $* p<.05 ; * * p .01$.

Table 3. Moderated multiple regression predicting postgame shift in evaluations of winning and losing team's chances

\begin{tabular}{|c|c|c|c|c|c|c|c|c|}
\hline \multirow[b]{2}{*}{ Predictor variable } & \multicolumn{4}{|c|}{ Shift in winner's chances } & \multicolumn{4}{|c|}{ Shift in loser's chances } \\
\hline & $B$ & $S E B$ & $\beta$ & $\Delta R^{2}$ & $B$ & $S E B$ & $\beta$ & $\Delta R^{2}$ \\
\hline Step 1 & & & & $.079 * *$ & & & & .037 \\
\hline Team supported $(\mathrm{TS})^{\mathrm{a}}$ & .923 & .335 & $.230 * *$ & & -.588 & .349 & -.144 & \\
\hline Team identification (TI) & .025 & .013 & .158 & & -.120 & .014 & -.125 & \\
\hline Step 2 & & & & $.037 *$ & & & & .00 \\
\hline $\mathrm{TS} \times \mathrm{TI}$ & .061 & .026 & $.267 *$ & & .001 & .028 & .005 & \\
\hline Overall $R$ & .340 & & & & 192 & & & \\
\hline Overall $R^{2}$ & .116 & & & & .037 & & & \\
\hline Adjusted $R^{2}$ & .096 & & & & .015 & & & \\
\hline Overall $F(3,132)$ & $5.759 * *$ & & & & 1.680 & & & \\
\hline
\end{tabular}

Note: $N=136$ for both analyses.

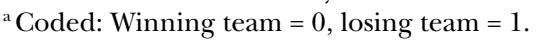

$* p<.05 ; * * p<.01$.

team identification $(\beta=.267, p<.05)$. None of the variables were significant predictors in the final equation for losing team shift (smallest $p=.095)$.

The specific form of the interaction between team supported and team identification was evaluated following the procedures suggested by Aiken and West (1991). For each shift measure, the interaction was graphed by inserting high (1 $S D$ above the mean) and low (1 SD below the mean) values for identification score into the regression equations for each team support group. Both graphs are shown in Figure 1. The significant interaction was further explored with simple slope analyses. These analyses revealed that for fans of the losing team, the regression of post-game shift in their evaluations of the winning team on team identification was significantly different from zero $(\beta=.357, t=3.027, p<.01)$. For fans of the winning (MSU) team, however, team identification was not a reliable predictor of post-game shift in evaluations of the winning team $(\beta=-.028, t<1.0)$. The regression of postgame shift in evaluation of the losing team on team identification indicated no significant difference from zero in either the slope for fans of the losing team $(\beta=-.121, t<1.0)$ or the slope for fans of the winning team $(\beta=-.128$, $t=-1.076, n s)$. Thus, increases in team identification are associated with increases in postgame evaluations of the winning team's initial chances by fans of the loser but not by fans of the 

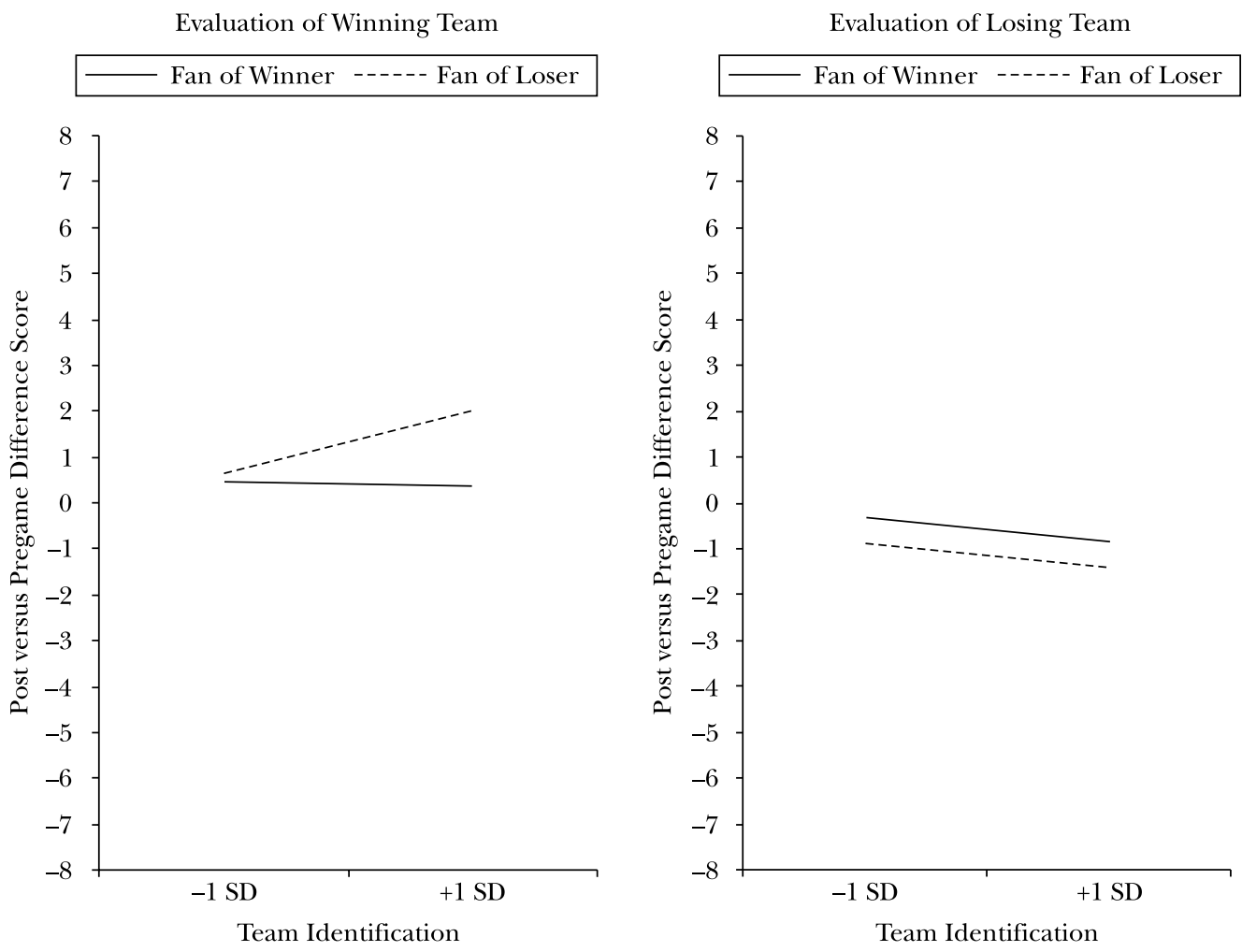

Figure 1. Relationship between team identification and amount of shift (postgame vs. pregame) in evaluations of the winning and losing team's initial chances of winning as a function of team supported.

winner, whereas increases in team identification are not significantly related to changes in postgame evaluations of the losing team's initial chances by fans of either team.

The last set of analyses examined the relationships between team identification, post-game shifts, and emotional reactions to the outcome. The initial analyses tested the prediction that level of team identification would be correlated with the intensity of emotional reactions to the contest. Consistent with expectations, a positive correlation emerged for fans of the winning team, $r(82)=.498, p<.01$ (i.e. highly identified fans felt happier about the outcome), while a negative correlation emerged for fans of the losing team, $r(50)=-.533, p<.01$ (i.e. highly identified fans felt more disappointed in the outcome). We then included degree of post-game shift in the analyses via use of mediated moderated regression to determine if differences in post-game shifts as a function of identification and team supported were mediated by emotional reaction to the outcome. Prior to conducting the analysis, the emotional reaction variable was centered as was the team identification variable. Interaction terms involving emotional reaction and team identification were based on the centered variables. Using the criteria for determining the presence of mediated moderation outlined by Muller, Judd, and Yzerbyt (2005), the analysis indicated that emotional reaction did not mediate the interaction between team supported and team identification for post-game shifts in evaluations of either the winning or the losing team. Mediated moderation is indicated when the magnitude (absolute value) of the interaction effect is reduced by the inclusion of the mediator (as a main effect and in an interaction term) in 
the model. However, for shifts in evaluations of the winning team, the interaction effect when the emotional reaction was included was actually nominally larger $(\beta=.489)$ than when the mediator was not included $(\beta=.267)$. For shifts in evaluation of the losing team, the absolute value of the interaction effect when the mediator of emotional reaction was added to the model $(\beta=-.005)$ was no different from the effect when the mediator was not in the model $(\beta=.005) .^{3}$ Thus, it appears that degree of happiness (or unhappiness) about the outcome of the game did not mediate the effects of the interaction between team supported and team identification on retrospective pessimism for evaluations of either the winning or the losing team.

\section{Discussion}

The current investigation was designed to extend the work of Tykocinski and colleagues (Tykocinski, 2001; Tykocinski et al., 2002) on retroactive pessimism, i.e. the tendency to perceive a negative outcome as having been inevitable. Using social identity theory as a framework (Hogg \& Abrams, 1988; Tajfel \& Turner, 1986), we hypothesized that such a tendency would be most prominent among highly identified group members (Branscombe et al., 1999; Wann \& Schrader, 2000). For these individuals, group threat has implications for their social identity and, therefore, they stand to benefit the most from coping strategies such as retroactive pessimism. The first series of analyses, conducted across level of identification, provided clear replication of Tykocinski's findings. Specifically, although fans of both teams exhibited retroactive pessimism by decreasing their evaluations of the chances for the losing team and increasing their ratings of the chances for the winning team, the effects were much more evident among those who were fans of the losing team. Because proactive pessimism and similar hindsight bias strategies are designed to assist in one's attempt to cope with a threat to a valued social identity (Blank \& Nestler, 2006), one would expect such a pattern because fans of the losing team would experience a greater threat than supporters of the winning team.
With respect to emotional responses to the outcome, our results once again replicated the work of Tykocinski. Specifically, we found that pre- to post-game shifts were associated with greater levels of disappointment for fans of the losing team, whereas a significant relationship was not found for supporters of the winning team. This is precisely the pattern of effects reported by Tykocinski et al. (2002) in their research on retroactive pessimism among soccer fans. Further, this pattern mirrors the results presented by Blank and Nestler (2006) in their work on German reactions to Leipzig, a city in Germany, not being selected as host of the Olympic Games and substantiates their conclusion that 'necessity impressions serve as a coping mechanism for disappointment' (p. 157). Thus, as with previous work on hindsight biases, assessing levels of disappointment provided additional understanding of group members' attempts to cope with threat. Consequently, future researchers should include this simple but informative item, thereby furthering our understanding of the relationships among disappointment (i.e. emotional impact of a threat), identification, and coping mechanisms. Researchers may also want to include assessments of collective (i.e. social) self-esteem (Luhtanen \& Crocker, 1991) given the possibility that increased use of retroactive pessimism may help in the maintenance of collective well-being.

However, it warrants mention that we assessed emotional responses in a rather simplistic fashion, namely, via a single Likert-scale item. Our decision to operationalize emotional responses in this fashion was a function of our desire to approximate Tykocinski's work as fully as possible. Selecting a different method of assessing emotional responses would have rendered direct comparisons more difficult. Given that (i) our work successfully replicated Tykoconski's, (ii) other researchers investigating hindsight biases have successful employed similarly simplistic assessments of emotional reactions (Blank \& Nestler, 2006), and (iii) single item assessments can be psychometrically sound (Kwon \& Trail, 2005; Rossiter, 2002), we are confident in our assessment of the respondents happiness/disappointment in the competition 
outcome. However, given the inherent dangers of using single-item measures (Churchill, 1979; Nunnally, 1978), future researchers should attempt to replicate the findings reported here with different, perhaps more sophisticated, operational definitions.

Although we were interested in replicating Tykocinski et al. (2002), the primary purpose of this investigation was to extend their research by including an examination of the supporters' level of team identification into the analyses. The results detailed earlier reveal that identification is a critical individual difference variable in understanding the use of retroactive pessimism. First, level of identification was significantly related to the intensity of emotional responses to the outcome. For fans of the winning team, higher levels of identification corresponded to greater levels of positive emotional reactions to the outcome, whereas fans of the losing team reported the opposite pattern of effect.

Second and most importantly, the tendency to retrospectively lower one's evaluations of a team's chances for success subsequent to group failure was more prominent among highly identified group members than those lower in identification (a pattern not mediated by disappointment). Increases in the use of retroactive pessimism were associated with increased levels of identification with the losing team and involved evaluations of the winning team's chances. Again, this finding fits well within the notion that retroactive pessimism allows individuals to better cope with a threat to their social identity. In our earlier discussion, we noted that fans of the losing team should be more likely to utilize retroactive pessimism because these fans experienced a threat (relative to fans of the winning team). This logic can be extended to include the identification level of these fans. That is, fans of the losing team who do not identify strongly with the team should not feel threatened when the team performs poorly because the role of team follower is not a central component of their social identity (i.e. these persons are not threatened by poor team performance). Conversely, persons with high levels of identification are threatened by the team's poor performance and thus, stand to gain the most from the use of retroactive pessimism.

Therefore, consistent with prior research (Branscombe et al., 1999; Doosje et al., 1998; Ouwerkerk et al., 1999), our data revealed that it was the combination of high levels of group identification and identity threat that led to the use of the coping strategy. This finding also compares nicely with the previously described work by Blank and Nestler (2006) on German reactions to Leipzig's failure to be awarded the Olympic Games. These authors found that increases in necessity (i.e. retroactive pessimism) were positively correlated with levels of commitment (e.g. support for the application) with the issue at hand. Although commitment and identification are not identical constructs, they share many commonalities and these terms are often used interchangeably (Wann, 2006). It is also interesting to note that Blank and Nestler (2006) found negative relationships between assessments of commitment and foreseeability. This suggests that, although identification is positively related to necessity judgments such as retroactive pessimism, identification may be negatively correlated with foreseeabilty. Specifically, had we asked participants about their perceptions of the foreseeability of the outcome (e.g. 'To what extent do you/did you know how the game would turn out?'), we may have found post-game versus pre-game responses to these items to be negatively correlated with identification. As Blank and Nestler (2006) note, admitting retrospectively that a negative outcome was foreseeable may provoke cognitive dissonance. That is, highly identified and loyal fans probably do not conclude post-game that 'I really knew we would lose' because such a statement lies in opposition to being a committed and loyal fan.

Additional analyses revealed that the retroactive pessimism exhibited by the highly identified fans of the losing team targeted their evaluations of the winning team's chances for success. That is, increased levels of identification for fans of the losing team corresponded to increased post-game evaluations of the winning team, but there were no significant changes in their evaluations of their own team. In essence, 
these fans chose to adjust their perceptions of the rival team rather than their own. In doing so, they were likely able to protect their perceptions of the quality of their team while retroactively attributing the outcome to the opposing team's ability. It appears to have been easier for these fans to conclude that the rival team was better than previously believed while maintaining consistent impressions of their ingroup team (e.g. it was easier to view the rival as better than to believe that their team was worse). Such an effect was detected previously by Wann and Dolan (1994) who found that sport fans (and in particular highly identified fans) increased their perceptions of an opponent's ability after watching their team lose to that opponent.

Finally, in terms of future research, it would be interesting to replicate the current work in an environment in which a group's successes were unexpected. In the work by Tykocinski et al. (2002), the outcome was expected (i.e. there was a clear favorite) while in the current investigation, because the teams were believed to be fairly evenly matched, a victory by either team was not out of the question. However, an unexpected outcome may lead to a different pattern of effects. That is, would fans of a losing team that was highly favored to win a competition conclude, retrospectively, that they never really had a chance? This seems unlikely. As noted by Branscombe et al. (1999), group members sometimes resort to more subtle coping strategies when intergroup comparisons are less ambiguous (e.g. such as when one's team is defeated by a clearly inferior opponent). In such a case, retroactive pessimism may not be a viable option for coping. Thus, one could predict that fans of a superior team would not resort to retroactive pessimism to ease the pain of a recent defeat at the hands of a lesser opponent. Rather, they would rely on a different form of coping such as increasing self-stereotyping (Spears et al., 1997) or increasing cohesion among members of the group (Doosje, Ellemers, \& Spears, 1995; Sutton, McDonald, Milne, \& Cimperman, 1997). Consequently, retroactive pessimism may be limited to situations in which the outcome was expected.

\section{Notes}

1. In the current work, we utilize Snyder's (1999) operationalization of coping, i.e. 'those responses that are effective in reducing an undesirable load (i.e. the psychological burden)' and whose effectiveness 'rests on its ability to reduce immediate distress, as well as to contribute to more long-term outcomes such as psychological well-being' (p. 5).

2. In addition to the correlation analyses, a simple mediated regression analysis was conducted following the procedure recommended by Baron and Kenny (1986) to determine if pre- to post-game shifts were mediated by emotional reaction. No significant mediation effect was found for evaluations of the winning team (indirect effect $=.01$ ) or the losing team (indirect effect $=0.0$ ) .

3. Further evidence against mediated moderation is provided by the failure of the analysis to exhibit any of the other required components of mediation identified by Muller et al. (2005) except for the presence of an overall significant moderation effect (as presented in Table 2). The relationship of team supported to emotional reaction did not depend upon team identification: emotional reaction differed as a function of team supported, $\beta=-.480, p<.01$, but the average partial effect of the mediator on post-game shift was statistically nonsignificant for both losing team and winning team evaluations, $\beta=-.005$ and $\beta=.180$, respectively. Furthermore, the partial effect of emotional reaction (the mediator) on post-game evaluation shifts did not depend upon level of team identification for either winning or losing team evaluations (the average relationship of team supported to the mediator was significant, $\beta=-.735, p<.01$, but the effect of the mediator on post-game shifts did not change significantly as a function of an increase in team identification for either losing or winning team evaluations, $\beta=-.007$ and $\beta=.133$, respectively).

\section{Acknowledgments}

The authors wish to thank three anonymous reviewers for their valuable contributions to this research. Portions of this research were presented at the Annual Meeting of the Association for the Advancement of Applied Sport Psychology, Philadelphia, October, 2003. 


\section{References}

Aiken, L. S., \& West, S. G. (1991). Multiple regression: Testing and interpreting interactions. Newbury Park, CA: SAGE.

Baron, R. M., \& Kenny, D. A. (1986). The moderator-mediator variable distinction in social psychological research: Conceptual, strategic, and statistical considerations. Journal of Personality and Social Psychology, 51, 1173-1182.

Blank, H., Fischer, V., \& Erdfelder, E. (2003). Hindsight bias in political elections. Memory, 11, 491-504.

Blank, H., \& Nestler, S. (2006). Perceiving events as both inevitable and unforeseeable in hindsight: The Leipzig candidacy for the Olympics. British Journal of Social Psychology, 45, 149-160.

Branscombe, N. R., Ellemers, N., Spears, R., \& Doosje, B. (1999). The context and content of social identity threat. In N. Ellemers, R. Spears, \& B. Doosje (Eds.), Social identity (pp. 35-58). Oxford, UK: Blackwell.

Branscombe, N. R., Wann, D. L., Noel, J. G., \& Coleman, J. (1993). In-group or out-group extremity: Importance of a threatened social identity. Personality and Social Psychology Bulletin, 19, 381-388.

Churchill, G. A., Jr. (1979). A paradigm for developing better measures of marketing constructs. Journal of Marketing Research, 16, 64-73.

Crocker, J., \& Major, B. (1989). Social stigma and self-esteem: The self-protective properties of stigma. Psychological Review, 96, 608-630.

Doosje, B., Branscombe, N. R., Spears, R., \& Manstead, A. S. R. (1998). Guilty by association: When one's group has a negative history. Journal of Personality and Social Psychology, 75, 872-886.

Doosje, B., Ellemers, N., \& Spears, R. (1995). Perceived intragroup variability as a function of group status and identification. Journal of Experimental Social Psychology, 31, 410-436.

Doosje, B., Ellemers, N., \& Spears, R. (1999). Commitment and intergroup behaviour. In N. Ellemers, R. Spears, \& B. Doosje (Eds.), Social identity (pp. 84-106). Oxford, UK: Blackwell.

Hawkins, S. E., \& Hastie, R. (1990). Hindsight: Biased judgment of past events after the outcomes are known. Psychological Bulletin, 107, 311-327.

Hirt, E. R., Zillmann, D., Erickson, G. A., \& Kennedy, C. (1992). Costs and benefits of allegiance: Changes in fans' self-ascribed competencies after team victory versus defeat.
Journal of Personality and Social Psychology, 63, 724-738.

Hogg, M. A., \& Abrams, D. (1988). Social identifications: A social psychology of intergroup relations and group processes. London: Routledge.

Kwon, H., \& Trail, G. (2005). The feasibility of single-item measures in sport loyalty research. Sport Management Review, 8, 69-89.

Luhtanen, R., \& Crocker, J. (1991). Self-esteem and intergroup comparison: Toward a theory of collective self-esteem. In J. Suls \& T. A. Wills (Eds.), Social comparisons: Contemporary theory and research (pp. 211-234). Hillsdale, NJ: Erlbaum.

Muller, D., Judd, C. M., \& Yzerbyt, V. Y. (2005). When moderation is mediated and mediation is moderated. Journal of Personality and Social Psychology, 89, 852-863.

Nunnally, J. C. (1978). Psychometric theory. McGraw-Hill: New York.

Ouwerkerk, J. W., Ellemers, N., \& de Gilder, D. (1999). Group commitment and individual effort in experimental and organizational contexts. In N. Ellemers, R. Spears, \& B. Doosje (Eds.), Social identity (pp. 184-204). Oxford, UK: Blackwell.

Rossiter, J. R. (2002). The C-OAR-SE procedure for scale development in marketing. International Journal of Research in Marketing, 19, 305-335.

Slovic, P., \& Fischhoff, B. (1977). On the psychology of experimental surprises. Journal of Experimental Psychology: Human Perception and Performance, 3, 455-551.

Snyder, C. R. (1999). Coping: Where have you been? In C. R. Snyder (Ed.), Coping: The psychology of what works (pp. 3-19). New York: Oxford University.

Spears, R., Doosje, B., \& Ellemers, N. (1997). Self-stereotyping in the face of threats to group status and distinctiveness: The role of group identification. Personality and Social Psychology Bulletin, 23, 538-553.

Sutton, W. A., McDonald, M. A., Milne, G. R., \& Cimperman, J. (1997). Creating and fostering fan identification in professional sports. Sport Marketing Quarterly, 6, 15-22.

Tajfel, H., \& Turner, J. C. (1986). The social identity theory of intergroup behavior. In S. Worchel \& W. Austin (Eds.), Psychology of intergroup relations (pp. 7-24). Chicago: Nelson-Hall.

Tykocinski, O. E. (2001). I never had a chance: Using hindsight tactics to mitigate disappointments. Personality and Social Psychology Bulletin, 27, 376-382. 
Tykocinski, O. E., Pick, D., \& Kedmi, D. (2002). Retroactive pessimism: A different kind of hindsight bias. European Journal of Social Psychology, 32, 577-588.

Wann, D. L. (2006). The causes and consequences of sport team identification. In A. A. Raney \& J. Bryant (Eds.), Handbook of sports and media (pp. 331-352). Mahwah, NJ: Erlbaum.

Wann, D. L., \& Branscombe, N. R. (1993). Sports fans: Measuring degree of identification with the team. International Journal of Sport Psychology, 24, $1-17$.

Wann, D. L., \& Dolan, T. J. (1994). Attributions of highly identified sports spectators. Journal of Social Psychology, 134, 783-792.

Wann, D. L., Dolan, T. J., McGeorge, K. K., \& Allison, J. A. (1994). Relationships between spectator identification and spectators' perceptions of influence, spectators' emotions, and competition outcome. Journal of Sport and Exercise Psychology, 16, 347-364.

Wann, D. L., \& Schrader, M. P. (2000).

Controllability and stability in the self-serving attributions of sport spectators. Journal of Social Psychology, 140, 160-168.

Paper received 20 June 2006; revised version accepted 4 March 2008.

\section{Biographical notes}

DANIEL L. WANN is professor of psychology at Murray State University and a member of the executive board of directors for the National Alliance for Youth Sports. His research interests center around sport fans and group identification.

FREDERICK G. GRIEVE is a professor of psychology and the coordinator of the clinical psychology master's program at Western Kentucky University. His research examines the behavior of sport fans and male body image.

PAULA J. WADDILL is professor of psychology at Murray State University with specializations in cognitive psychology and statistics/research design. Her current research interests include the roles that mental representations and inferences play in memory and decision making.

JENNIFER MARTIN received her masters degree in clinical psychology from Murray State University. 